\title{
Oral allergy syndrome and risk of food-related anaphylaxis: a cross-sectional survey analysis
}

\author{
Amanda Jagdis ${ }^{1 *}$, Amin Kanani ${ }^{2}$, Donald Stark ${ }^{3}$ \\ From Canadian Society of Allergy and Clinical Immunology Annual Scientific Meeting 2011 \\ Quebec, Canada. 20-23 October 2011
}

\section{Background}

Oral Allergy Syndrome (OAS) is an IgE-mediated allergic response to fresh fruits, nuts and vegetables caused by cross-reactivity between pollen allergens and structurally similar food proteins. Alder pollen is a prominent allergen in coastal British Columbia, present at high levels from February- April. We hypothesized that this exposure may lead to increased prevalence of Alder pollen allergy and OAS. We sought to determine our population-based prevalence, cross-reactivity patterns, and incidence of food-related anaphylaxis.

\section{Methods}

A chart review of 574 allergic rhinitis patients seen from January 2010 - June 2011 was performed. 274 OAS patients were invited to participate in an online, telephone or in-person survey. Patients completing the survey in the clinic were invited to undergo a panel of skin prick tests.

\section{Results}

63 patients were surveyed, 14 underwent skin testing. Patient characteristics included: median age $=37$ (range $20-77$ ), $83 \%$ female, $36 \%$ atopic dermatitis, $24 \%$ asthma. OAS prevalence among seasonal allergic rhinitis patients $=242 / 574(42 \%) .14 / 14$ patients were skin test positive for Alder and Birch. The most common OAS foods were apple $44 / 63(70 \%)$, cherry $37 / 63(59 \%)$, and peach $38 / 63$ (60\%). 28 had epinephrine auto-injector devices; 4 had used their device; $6 / 10$ reactions involved foods that had caused OAS including apple, celery, green pepper, tomato, peanut, walnut.

'Department of Internal Medicine, Faculty of Medicine, University of British Columbia, Vancouver, BC, Canada

Full list of author information is available at the end of the article

\section{Conclusions}

In our population, the prevalence of OAS was slightly lower than expected at $42 \%$. The most common OAS/ pollen allergy was Alder, correlating with the high Alder pollen exposure in coastal British Columbia. OAS may be associated with serious reactions requiring use of epinephrine.

\section{Author details}

${ }^{1}$ Department of Internal Medicine, Faculty of Medicine, University of British Columbia, Vancouver, BC, Canada. 'Division of Allergy and Immunology, Department of Internal Medicine, Faculty of Medicine, University of British Columbia, Vancouver, BC, Canada. 'Division of Allergy and Immunology, Clinical associate professor, Department of Internal Medicine, Faculty of Medicine, University of British Columbia, Vancouver, BC, Canada.

Published: 14 November 2011

doi:10.1186/1710-1492-7-S2-A2

Cite this article as: Jagdis et al:: Oral allergy syndrome and risk of foodrelated anaphylaxis: a cross-sectional survey analysis. Allergy, Asthma \& Clinical Immunology 2011 7(Suppl 2):A2.

Submit your next manuscript to BioMed Central and take full advantage of:

- Convenient online submission

- Thorough peer review

- No space constraints or color figure charges

- Immediate publication on acceptance

- Inclusion in PubMed, CAS, Scopus and Google Scholar

- Research which is freely available for redistribution

\section{() Biomed Central}

